\title{
COMMONWEALTH SCIENTIFIC AND INDUSTRIAL RESEARCH ORGANIZATION, AUSTRALIA
}

\section{CHEMICAL RESEARCH LABORATORIES}

$\mathrm{T}$ HE Commonwealth Scientific and Industrial Research Organization (Australia) has changed the status of one of its largest research groups, the Division of Industrial Chemistry, which has its headquarters at Fishermen's Bend, Melbourne. The Division will in future be known as the C.S.I.R.O. Chemical Research Laboratories, and its chief, Dr. I. W. Wark, becomes the first director of the Laboratories. Two of the largest Sections of the Laboratories will become Divisions (the name used for the major units of C.S.I.R.O.'s activities). Dr. A. L. G. Rees will become chief of the new Division of Chemical Physics and Dr. K. L. Sutherland will become chief of the new Division of Physical Chemistry.

These two new Divisions together with the remaining four major Sections will comprise the Chemical Research Laboratories. These sections and their officers-in-charge are as follows: Minerals Utilization (Mr. R. G. Thomas) ; Organic Chemistry (Dr. H. H. Hatt); Cement and Ceramics (Mr. A. J. Gaskin); Chemical Engineering (Dr. H. R. C. Pratt). The Foundry Sands Section will continue to be affiliated with the group.

Dr. Wark has been chief of the C.S.I.R.O. Division of Industrial Chemistry since its formation in 1940 . Under his guidance this group has grown until it now has a research staff of one hundred and a total staff of three hundred.

More than a third of the research staff has been recruited from overseas, and about half of the Australians have studied abroad for higher degrees.

An adventurous outlook on research within the Chemical Research Laboratories has produced outstanding contributions in many phases of chemical discovery, both in basic science and in the solution of practical problems.

Some of C.S.I.R.O.'s more spectacular applications of science have come from the Chemical Research Laboratories. These include the process using cetyl alcohol for controlling evaporation from dams and reservoirs; the process for separating hafnium from zirconium which is of significance for atomic-powered submarines; and a process for recovering uranium from its ores.

Dr. Wark's own personal research was concerned with the theory of the flotation process for separating minerals from ores, which is of major importance to the mining industry. His pioneering work as a physical chemist in this field gained for him a worldwide reputation, and his book, "Principles of Flotation", first published in 1938, became recog- nized as a classic on the subject. $\mathrm{He}$ is a Fellow of the Australian Academy of Science. For many years he has taken a prominent part in the affairs of the Royal Australian Chemical Institute and has done much to gain a wider appreciation of the importance of chemistry and of science generally. He served as president of the Institute during the year $1957-58$.

Dr. A. L. G. Rees, chief of the new Division of Chemical Physics, began his scientific career with a brief temporary lectureship in the University of Western Australia; then he became Beit Fellow at the Imperial College of Science and Technology, London. In 1941 he was awarded the Ph.D. of the University of London and joined the Philips organization in England as head of the Fundamental Research Group. He held this post until 1944, when he was appointed to C.S.I.R.O. to form the Chemical Physics Section. He has undertaken research into the structure and properties of materials. He is the author of many scientific papers on spectroscopy, electron diffraction, electron microscopy, Iuminescence and allied subjects. $\mathrm{He}$ is the author of a book- "Chemistry of the Defect Solid State" (Methuen, London, 1954). $\mathrm{He}$ is a Fellow of the Australian Academy of Science and of the Royal Australian Chemical Institute. He received the Institute's Rennie Memorial Medal in 1945 and its H. G. Smith Memorial Medal in 1951.

Dr. K. L. Sutherland, chief of the new Division of Physical Chemistry, began his research career on the froth flotation of minerals, which was supported by a group of mining companies, in the University of Melbourne. $\mathrm{He}$ joined C.S.I.R.O. in 1940 and continued his work on flotation, concentrating particularly on the kinetics of the process. He has gained world-wide recognition for his work in this field. In 1947 he was awarded the Davy Faraday Fellowship of the Royal Institution and worked in London for a period. Later, he was awarded the degrees of D.Se. of the University of Melbourne and Ph.D. of the University of London. He returned to the Division of Industrial Chemistry in 1950. He recently collaborated with Dr. I. W. Wark in the revision of the second edition of Dr. Wark's book, "Principles of Flotation". $\mathrm{He}$ is a Fellow of the Royal Australian Chemical Institute. He received the Institute's Rennie Memorial Medal in 1943 and its H. G. Smith Memorial Medal in 1957. The University of Melbourne awarded him the Grimwade Prize in 1943 and the Syme Prize in 1948.

\section{RURAL RESEARCH}

$\mathrm{T}$ HE lack of agricultural development in the comparatively well-watered section of tropical Australia has long presented an enigma. The region has been either hailed as a land of unlimited potentialities or written off as virtually worthless.

It is only in the post-war period that a systematic effort has been made to define the agricultural and pastoral potentialities of the land and solve the problems limiting its exploitation. Officers of the Division of Land Research and Regional Survey of the Commonwealth Scientific and Industrial Research Organization have been in the forefront of this effort and have shown already that large areas of Northern Australia are capable of agricultural 
development. By a series of broad-scale land-use potentiality surveys they classified and defined the land. Then Research Stations were established at two type locations to study crop and pasture production. The first of these was for dryland agriculture at Katherine, about two hundred miles south of Darwin, and the second was a joint irrigation venture with the Western Australian Department of Agriculture on the Ord River in the East Kimberleys.

Accounts are given in "Rural Research in C.S.I.R.O." of the successful outcome of research at these stations over the past decade (25, September 1958). Reasons for past failures have been explained, and, with the new knowledge, crops such as sugar, rice, cotton and peanuts have been cultivated successfully under experimental conditions. Returns from peanuts as a major cash crop at Katherine and successes with subsidiary crops offer promise for the establishment of profitable mixed farming with associated livestock industries over large areas. At the Kimberley Research Station, sugar has done extremely well under irrigation, while rice, cotton and safflower are very promising. These experimental results must be supplemented by further economic data from farm-scale trials before settlement can be planned.

This information is now being sought as part of a joint venture with the Western Australian Department of Agriculture.

\section{PARAPSYCHOLOGY}

$\mathrm{T}$ HE Institute for the Study of Mental Images was started informally in May 1956 as a private venture "in order to evaluate the status and behaviour of mental images not immediately related to sensory stimuli, and to pursue theoretical investigations in general psychophysical theory". An investigation of hypnagogic images is claimed to be in progress, assisted by a grant from the Parapsychology Foundation, New York. Three communications have now been published*.

In fairness to the authors, it must be made clear at once that their tripartite paper is a serious and learned essay in the philosophy of science-or in scientific philosophy, as it might better be termed in this case. Of its type, it is good. The technicalities are mainly in the language of physics, which most scientific readers will find more to their taste than symbolic logic ; the text, though it could be clearer, compares well with that of the majority of disquisitions of this type; and the authors have avoided the more obvious traps. On the other hand, they have had to pay the price of extreme generality, abstraction and impartiality by seeming a little inconclusive.

But let them speak for themselves. The paper attempts "to bridge the considerable gap between psychiatry and advanced physics as the first step towards a psycho-physical theory of the world. A beginning is made by following Sir Arthur Eddington in questioning the usual separability assumptions which underlie all scientific investigations". (By "psychiatry" they clearly mean a class of psychological theory, not the day-to-day practice of the art.) Their purpose is "to outline a psycho-physical world theory which is both self-consistent and of sufficient generality to provide a framework for the discussion of all widely held opinions. ... If this ideal could be realized, men might indeed become as little children, and continue throughout their lives to learn by experience, and to realize their mistakes, without becoming involved in paranoid ideological systems-whether religious, scientific, political or psychoanalytic".

They add, modestly enough, that their theory "has two of the chief characteristics of all paranoid

* "Introduction to Parapsychology". By c. C. L. Gregory and Anita Kohsen. Communications of the Institute for the Study of Mental Images. Vol. 1, Part 1 (1957); Parts 2 and 3 (1958). (Church each. phantasy, i.e., that it is self-consistent and incomplete".

The particular "widely-held opinions" exemplified are, of course, those related to the credibility (in the ordinary sense) of parapsychological phenomena and 'miracles' in general. The central point appears to be that it is illogical to claim that an alleged paranormal phenomenon is impossible by appealing to a scientific argument which rests on an assumption that absolutely precludes the phenomenon; one might as well say simply: "I do not believe it because it contradicts what I do believe". The psychiatrist, Dr. Michael Balint, is taken to task for falling into this elementary trap in connexion with the Lourdes 'miracles'. He is quoted as saying, in effect, that the criteria of cure (for example, that it must be instantaneous) are so unrealistic as to force the doctors concerned to distort the facts. It is true that Dr. Balint is out of his depth in these logical waters, or he would have realized that all arbitrary criteria (including that graven image, 'statistical significance') distort facts; but he is a practising clinician, and was clearly, though perhaps unwittingly, giving a clinical opinion rather than a sample of pure reason.

The authors of this paper, on the other hand, instead of taking sides, have attempted to found a system of thought in which it will not be necessary to take sides; in which what we now have to call either supernatural or bogus will be seen as natural. This ambitious project may be attempted in innumerable ways, varying from the easy to the impossible. The easiest way is simply to assert that all things are possible. The respectable empiricist who insists that no duly authenticated observation should be rejected on theoretical grounds evades being charged with this unlimited credulity at the risk of being challenged on his standard of due authentication. It is a weakness of this paper that it does not adequately meet the challenge.

So far as the authors' discursive style reveals, their basic strategy is to invoke the well-known common cause type of theory. Thus, if the universe is a gigantic statistical family tree, significant correlations of some kind should crop up occasionally in card-guessing experiments and the like. The interestlies, not in the general proposition as such, but in how it is handled; here the authors' many well-informed and thought-provoking remarks are marred by a disappointing reluctance to come to the point. W. E. HICK 